Research Article

\title{
Seismic Performance Evaluation of Buried Sewage Collection Pipelines
}

\begin{abstract}
Abolfazl Rahimi' ${ }^{1}$ and Mohammad Rezaii $\mathbb{i D}^{2}$
${ }^{1}$ Department of Civil Engineering, Islamic Azad University, Gorgan, Iran

${ }^{2}$ Department of Civil Engineering, NIT, Babol, Iran

Correspondence should be addressed to Mohammad Rezaii; rezaii@abfagolestan.ir

Received 26 November 2020; Revised 16 December 2020; Accepted 15 January 2021; Published 29 January 2021

Academic Editor: Seyed Mahdi Seyed Kolbadi

Copyright $(2021$ Abolfazl Rahimi and Mohammad Rezaii. This is an open access article distributed under the Creative Commons Attribution License, which permits unrestricted use, distribution, and reproduction in any medium, provided the original work is properly cited.

One of the systems which is damaged because of earthquake is an urban wastewater network. In this paper, it is tried to study the damages occurred on urban wastewater networks in a selected network. The most important definitions by the network about some branches of the wastewater network and relevant reformations are studied. Then, the function of pipeline networks buried by the previous earthquake is studied and also it is proceeded about the research studies done regarding the relationships dominant on susceptibility in which some of the mentioned relationships are studied. The statistical society of some methods used in this research is studied, and the software applied in this part is introduced. Finally, the data of the output results are analysed in which the results obtained by this research are including the output drawings of the software GIS that demonstrate the occurred damages in applied and clear way. Some suggestions for using the aforesaid results by the researchers and authorities, especially disaster headquarter, have been presented. The results of this study showed that the assumptions and also the modelling process have handled the simulation well and this process is an effective method in decision making.
\end{abstract}

\section{Introduction}

Lifeline refers to a set of structures, facilities, and installation which play a pivotal role in storing, supplying, transferring, and distributing basic necessities, such as water, electricity, and gas, or collecting, storing, purifying, and recycling wastewater and other trash, or even making communication, such as landline, cell phone, Internet, and data [1]. As their names suggest, broadness and continuous performance are defining characteristics of such structures as mentioned in Figure $1[2]$.

These structures share common features. Obviously, lifeline function a significant performance in the city and supply basic necessities. As an illustration of this, the wastewater system is a most important lifeline. Raw sewage always has a great deal of matters having detrimental effects on beings which would result in even unknown infectious diseases, for example, pestilence and cholera. In addition, combination of sewer gases, such as methane, ethane, and benzene, with air increases the likelihood of explosion [3]. In general speaking, there are two analytical and statistic approaches to studying susceptibility of underground pipelines when it comes to earthquake. As such, the analytical view aims to present relations in order to find strain in pipes through physical laws. Considering this view, recent literature is setting out to find how such seismic parameters such as MMI, PG, and PGV bring about destruction. A sewage system is made up of linear and stationary structures (Figure 2).

The sewage system pipelines are classified into seven groups. By moving from top to down, the importance and diameter of pipes are decreased. Table 1 illustrates the classification. It is worth mentioning that material of pipes has dramatically affected last earthquake data. As fittings of the sewage system have not been made to endure pressure, they are weak. Rigid fittings refer to those that avoid two adjacent parts from displacement at the end, while flexible fittings allow two adjacent parts to locally rotate or transfer. 


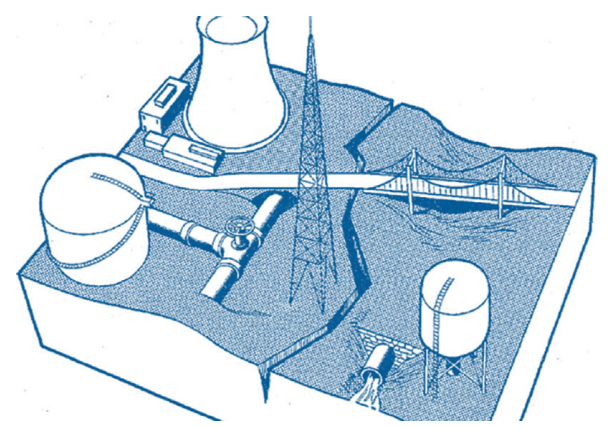

FIgURE 1: Scheme of lifelines.

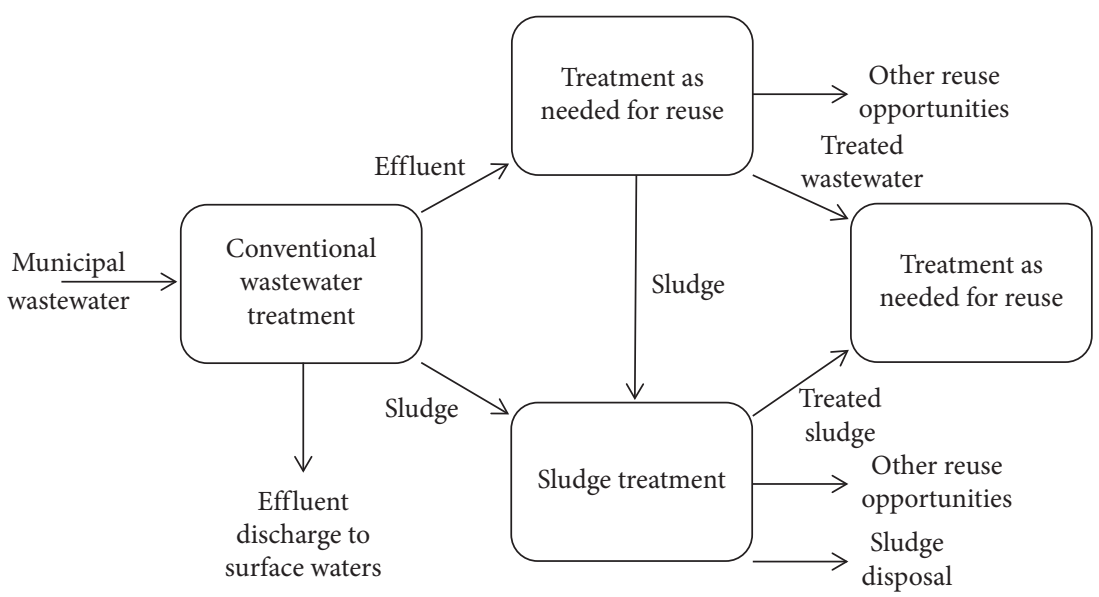

FIgURE 2: The scheme of a sewage system.

TABLE 1: Classification of the sewage system parts into linear and stationary.

\begin{tabular}{lc}
\hline $\begin{array}{l}\text { Type of the sewage } \\
\text { system component }\end{array}$ & Title of component \\
\hline $\begin{array}{l}\text { Stationary } \\
\text { Stationary }\end{array}$ & $\begin{array}{c}\text { Installation of sewage storage including } \\
\text { surface and ground basins } \\
\text { Installation for pumping }\end{array}$ \\
$\begin{array}{l}\text { Linear } \\
\text { Stationary } \\
\text { Linear }\end{array}$ & $\begin{array}{c}\text { Pipelines and ground main transfer } \\
\text { tunnel }\end{array}$ \\
$\begin{array}{l}\text { Stationary } \\
\text { Stationary }\end{array}$ & $\begin{array}{c}\text { Sewage-treatment plant } \\
\text { Pipelines for collecting sewage } \\
\text { Stationary }\end{array}$ \\
\hline
\end{tabular}

Sewage pipes and fittings are commonly made up of ceramic, concrete, cement asbestos, plastic, poly ethylene, UPVC, GRP, cast iron, and steel.

Iran is located on the Alp belt extending from the Alps Mountains to the Mediterranean Sea. Iran's plate consisted of Iran, Arabian, and Eurasian plates. Arabian plate pulls that of Iran. Zagros pressure region as well as mountains shows a common boundary between the two plates which has resulted in reverse faults. On the other hand, Iran's plate is surrounded by the Eurasian, Indian, and Anatolian plates from the north, east, and west, respectively. As such, pressure arising from the Arabian plate prevents Iranian plate from any transfer.
According to the Lifeline Earthquake Engineering Council, founded by the US Civil Engineering Council in 1974, it has been estimated that almost half of pipelines in Iran are at the risk of bursting in case of happening an earthquakes. On the other hand, although behaviour of ground pipelines has been studied during 10 last years, there is much room for argument. The direct relationship between the sewage system and public health, on the one hand, and having difficulty in finding location of leakage and breakage in pipes due to force of gravity in the sewage system after an earthquake taken place on the other hand, attaches importance to study susceptibility of the system. In addition, considering depth of the sewage system replacing and fixing damaged pipes would be extremely costly. So far, a lot of research has been done on the different functions of buried pipes. These studies have been conducted to better identify the behaviours of these sensitive infrastructures. In this study, the behaviour of these structures in the face of earthquake force for a relatively large area has been evaluated.

\section{Literature Review}

According to this analytical method, the results offered by Chu and Shah [4], as well as Goodling and Iqbal [5], suggest that inlet and outlet branches of the bended pipes seemed to be flexible but the sag assumed rigid; that is to say, they considered no relative rotation resulting from bending 
between inlet and outlet tangents. Moreover, relocation arising from slipping $(\Delta)$ measured by subtracting the relocation of a piece of pipe $(p \Delta)$ from relocation of soil $(s \Delta)$. Although the previous method assumed bending rigid, there tends to be some transformations in sags creating tendency to decrease in flexural moment.

Goodling [5] put forward equations based on analysing bending in thin-walled curved pipes. In a research study, [6] suggested a method for predicting relocation of the sag in which the Riley wave was assumed as a transmittal sine wave with limited wave length. In the same token, relocation of the pipe was assumed equal to that of ground where displacement of ground was zero, and they developed a simple equation for pipe strain in the point of sags based on correspondent structural analyses. They assumed effective length $\left(L^{\prime}\right)$ one-fourth of the wave length, so anchors could be measured by virtue of displacement compatibility equations in the curve.

Takada and Tanabe [7] put forward knee and T-joints are more susceptible to damage than other parts of a pipeline and maximum tensile pressure can affect them. In 2003, O'Rourke and McLaughlin developed a two-dimensional finite-element model as their PhD dissertation. They entered a quasistatic sine Riley wave into the numerical model and compared results obtained from a steel pipe having a diameter and thickness of 24 and 5 inch in a sand soil with a reduction factor (0.6) with that of obtained by Shah and Chu [4] as well as [6] for a flat surface steel.

Moreover, O'Rourke and Jeon [1] utilized a finite-element model developed in Nastran software to stimulate the problem and comparing analytical results. They assumed the pipe as a column element for modelling, and each bending had a length of 125 meters equal to one-fourth of a wave length having 500 meters. To verify this model, data collected from the analytical method were compared with that of the finite-element model. So, it was found that results obtained from the analytical method were almost better in all cases. As can be seen from prior works, most of numerical analyses concerning were quasistatic; however, studies on dynamic behaviour of pipe under earthquake loading are still lacking.

In 2008, F. R. Rofooei and R. Qorbani did a research on continuous pipes assuming vertical wave propagation and then compared obtained strain results with that of observed in a pipe having a knee-joint. Results showed that the existent sag led to an increase in strain and pressure in the knee-joint than a continuous pipe. Moreover, Takada et al. [8] did a numerical research on a set of pipes combining $T$ and knee-joint and showed that the seismic behaviour of a pipe network was more than a continuous one. In addition, adjacent pipes showed inconsiderable increased behaviour than patchy ones.

Dai et al. [9] studied about analysis and comparison of long-distance pipeline failures, and they found that according to the statistical results, PNGPC is not very far compared with foreign countries. There are still some aspects both in technology and in management that should be improved, such as quality of manufacture and construction of pipeline and third-party monitoring. Also, Yang et al. [10] did research about numerical simulation of pipeline-pavement damage caused by explosion of leakage gas in buried pipelines and showed that the results can provide theoretical basis for municipal pipeline construction design and urban safety planning and provide references for the risk assessment of gas explosion in buried pipelines.

2.1. New Zealand Earthquake. Christchurch is New Zealand's second biggest city. Its sewage system covers almost 150,000 families. Although, the system is made up of concrete, ceramic, UPVC, and asbestos pipes, it has a high percentage of concrete one. An earthquake measuring 7.1 on the Richter scale hit the city on 4th September 2010 (Figure 3 ). The sewage system was badly destroyed. Demolition rate of pipes made up of concrete and reinforced concrete (0.9) increases the likelihood of corrosion [11].

2.2. Japan Earthquakes. An earthquake measuring 6.8 on the Richter scale, called Nigata-Ken Chuetsu, hit the city in October 2004. Destruction of the sewage-treatment plant led to flow of raw sewage into the city, to such an extent that 151 kilometer sewage pipeline was destroyed and 2056 manholes were also damaged. The greatest damage recorded for tucking water behind manholes and pipes which not only generated heavy traffic but also caused failure to pump houses' sewage. Another earthquake measuring 7.5 on the Richter scale hit Nigata, Japan, on 16th January 1964. Over $470 \mathrm{~km}$ pipeline, namely, $68 \%$ of pipes, is damaged. The most destruction was recorded for cast iron pipes and joints. According to data, other pipes, especially those with small diameter, showed more damage due to bending. Many pipes and installation became visible on the ground because of soil liquefaction. In addition, slope of the soil is also considered as an important factor in damages [12].

2.3. Manjil Earthquake, Iran (1990). An earthquake hit Rodbar and Manjil, Iran, on 21st July 1990. It caused severe damage to several buildings, roads, installation, and even the Sefidrood concrete dam [13]. There are still insufficient data for the extent of damage to the water supply system. Although buildings' water pipes had been badly damaged, main pipelines of the city water supply system were in a satisfactory condition thanks to putting new pipes in depth (Figure 4).

2.4. Bam Earthquake (2003). An earthquake measuring 6.8 on the Richter scale struck Bam, Iran, on 26 December 2003. The city had a total population of 12000 . According to reports, asbestos fittings of pipes had been damaged but the main water supply system was slightly damaged [14]. Although water gushed from broken domestic pipes, water tanks were not badly damaged, mainly because they were underground (Figure 5).

\section{Material and Methods}

3.1. Effective Factors Causing Damage to Pipelines after Occurrence of an Earthquake. Multiple parameters have impact 


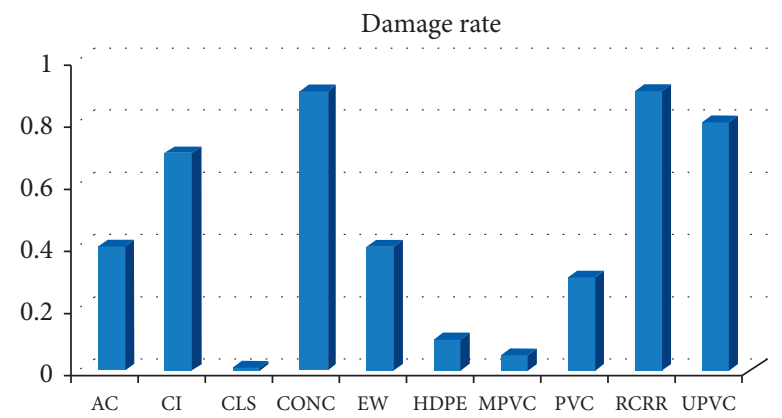

Figure 3: Demolition rate of pipelines considering their type in the New Zealand earthquake.
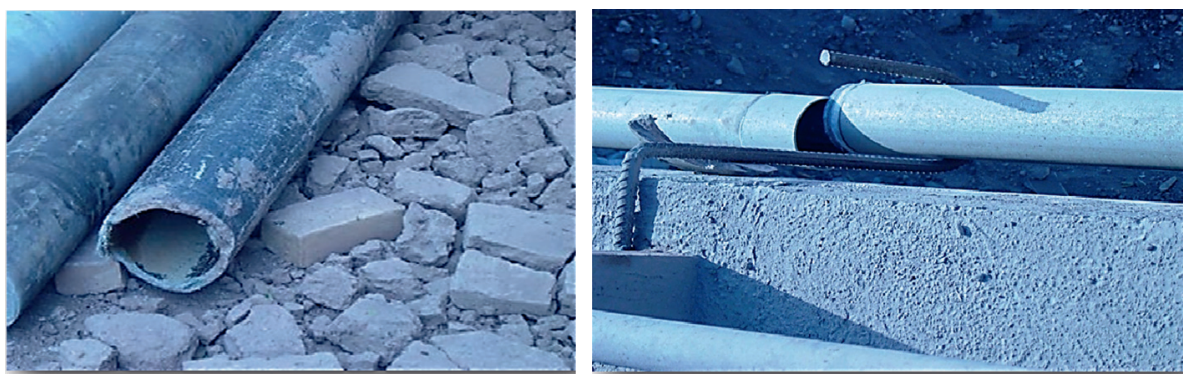

FIgURE 4: Damage occurred from Manjil earthquake.
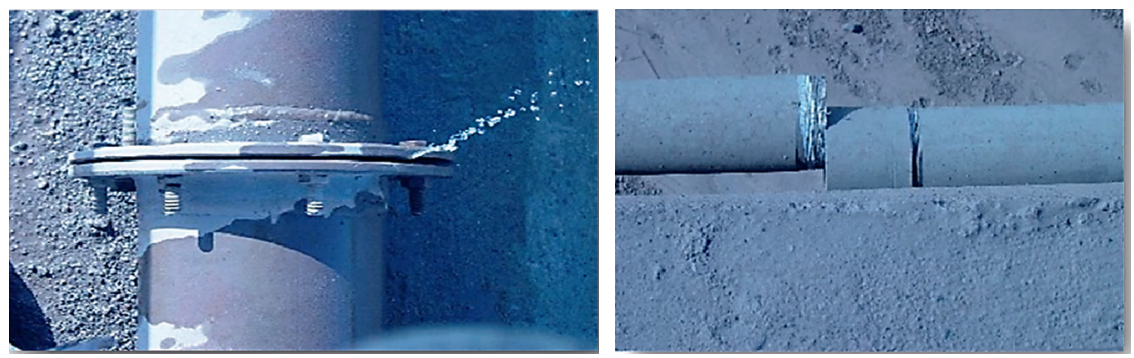

FIGURE 5: Damage occurred from Bam earthquake.

on damage to underground pipelines after occurring an earthquake. In general, characteristics of a pipeline, soil, and magnitude of an earthquake affect the seismic behaviour of the pipeline. As such, there are considerable factors having effect on the seismic behaviour of buried pipelines. In a research, Eguchi et al. studied factors affecting susceptibility of buried pipelines when an earthquake happens through analysing damage to the buildings destroyed in the San Francisco earthquake [15]. Evidence suggested that the devastating effect of faulting was much more than distortion due to earthquake movements. As a result, the closer a building is to the fault, the worse it would be destroyed. A pipeline would be inevitably face to more dangers, due to its extent, than other installations which cover a small area, simply because long pipelines are spread over regions having active faults or soil liquefaction. The term faulting is meant fracture of faults which is happened on the ground. There are three main types of faulting, including horizontal, vertical, or a combination of them. Installations located on the fault line are much more susceptible to the earthquake (Figure 6).

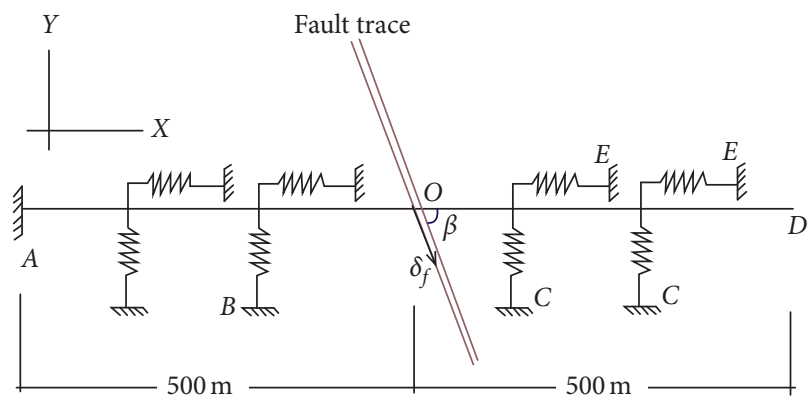

FIGURE 6: Ideal structural model during faulting.

Figure 6 shows an ideal structural model on a fault line, and the probability and extent of soil liquefaction will increase by increase in the continuance in earthquake. Soil liquefaction as well as lateral movements is viewed as devastating parameters which may lead to bury surface structures under soil or help underground structures to become visible. Shaking cause to compress soil, and subsidence is occurred. However, the extent of persistent 
relocation due to subsidence is less than that of due to soil liquefaction. Notwithstanding, subsidence is of importance because of making heterogeneous dislocations in soil.

\subsection{Features of the Pipeline Affecting Susceptibility of the} Buried Pipelines due to an Earthquake. Most of parameters affecting susceptibility of buried pipelines due to an earthquake have much to do with characteristics of the pipeline. Prior studies showed that type of the pipe plays a pivotal role. To put it simply, its flexibility helps the piping system because it leads to easily movement of soil along with the pipe, which prevent the pipe from bursting during an earthquake. Increase in the internal diameter of pipelines decreases both bending and axial tensions due to affecting soil-pipe interaction. Final conditions have marginal effect on tensions created in cross sections when it comes to length of pipe. With regard to data collected from the analysis, it is highly likely that the pipe will rupture at its junction with other installations, such as manholes and storages, than other sections of the pipeline (Figure 7-9).

The pipeline bears lateral loads during an earthquake which it oscillates pipes and cuts their connections with the saddle. However, bracing spaces helps the system not to be devastated. Figure 10 illustrates demolition of pipes' support due to soil liquefaction in the Northbridge earthquake (1994).

However, seismic and flexible joints have been found to suggest great function during an earthquake which it leads to decrease in demolition of the water supply system. On the other hand, accruing to data collected from prior research, continuous pipes, such as the ones made up of steel with welded joints, have shown greater function than sectional pipes with lots of joints. In addition, the extent of demolition observed for asbestos pipes in Loma Prieta (1989) and Northridge (1994) earthquakes was less than that recorded for Mexico City earthquake (1985).

Researchers also argue that connection behaviour would prove to be linear when pipes' relative rotation is 0.05 radian. Moreover, bending experiments on fittings used in flexible cast iron pipes having rubber-made washers and different diameters showed that rotation of joints is done around the pipe. Improper hardness distribution is the leading cause of most of the destructions of the water supply system. As a result, relocations arising from such shakes are different and cause to break joints between pipes (Figures 11 and 12).

\subsection{Methods of Studying the Seismic Behaviour of a Pipeline.} With regard to the destructions left after earthquakes, researchers set the stage to conduct a comprehensive study in order to develop some methods to find how seismic behaviour affects the pipelines. The methods are generally divided into three groups, including approximate analysis [16], accurate analysis, and building code methods. Shakes arising from an earthquake go through many changes due to several reasons before happening which will affect structures in different ways. Initial works in the field of buried pipelines focused preliminary on the main factor, that is to say, the path through which waves move. In addition, as can be seen

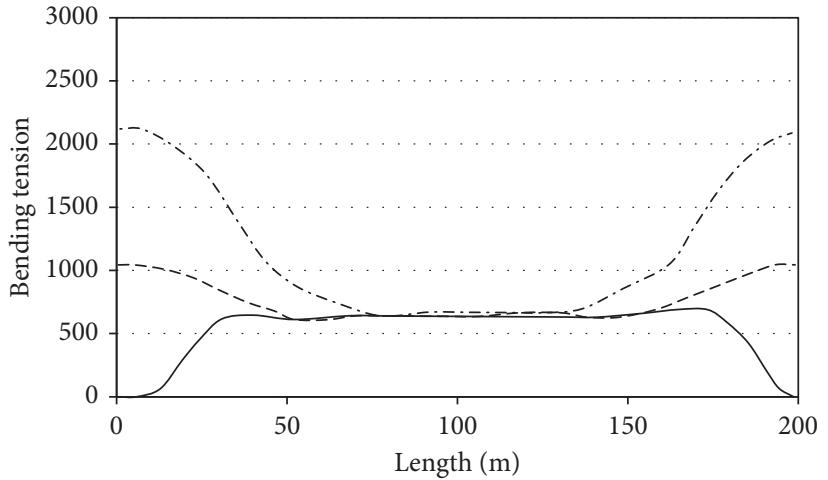

FIgURE 7: Variation in the extent of maximum bending tensions along the pipeline with different final conditions.

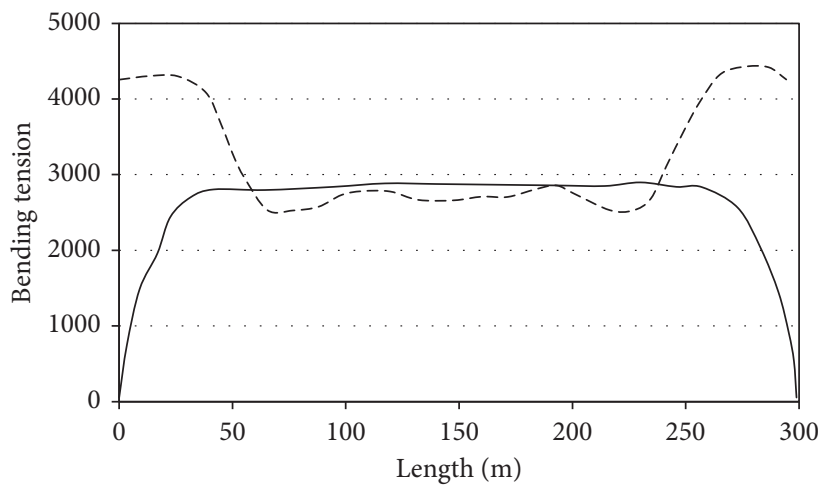

FIgURE 8: Variation in the extent of maximum axial tensions along the pipeline with different final conditions.

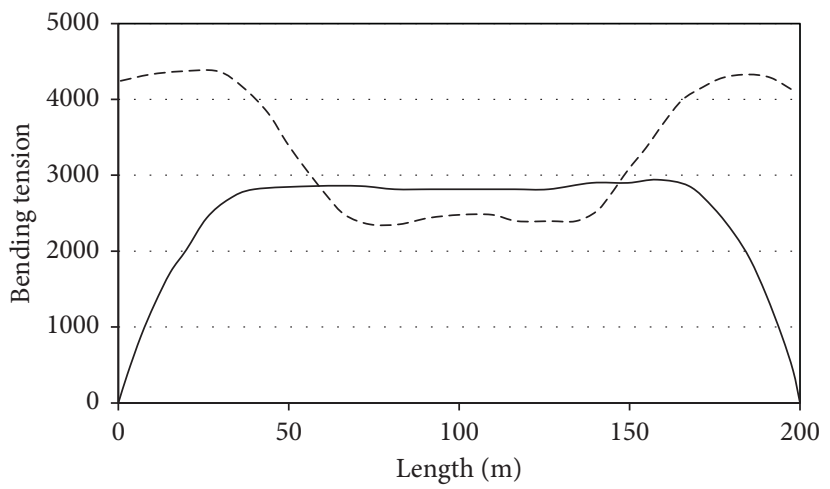

FIGURE 9: Variation in the extent of maximum axial tensions along the pipeline with different final conditions.

from numerical calculations, its effect has been considered in the form of a semistatic factor.

Regarding dynamic analyses done on buried pipelines, especially on their bending points, the impact of this factor has omitted, and pipes were only analysed by taking vertical distribution and synchronous shakes throughout all points into account. Wave propagation velocity functions as a leading parameter to calculate strain. Shear wave velocity was used to calculate the extent of axial strain in areas having 


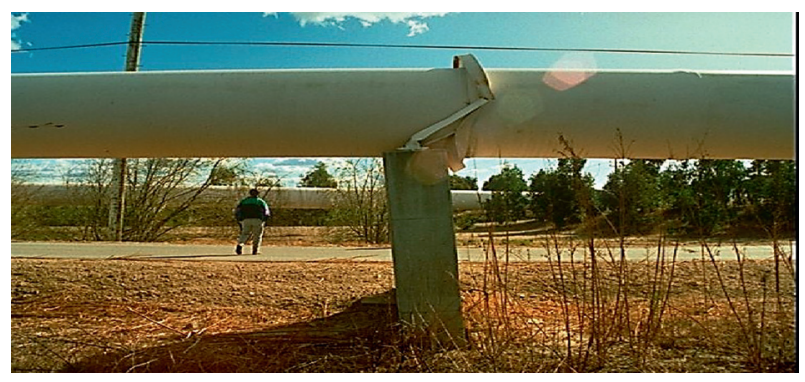

Figure 10: Demolition of pipes' support due to soil liquefaction in the Northbridge earthquake (1994).

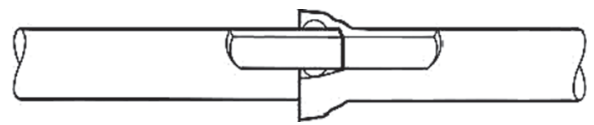

FIGURE 11: Cracks observed in the joint between a restrained weak pipe and an unrestrained one [11].

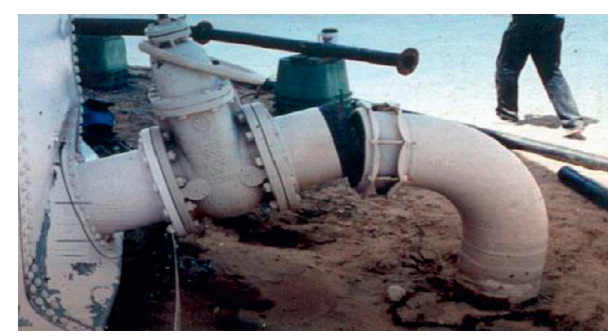

FIgURE 12: Cracks in the pipe connected to the storage (ALA 2002).

focal length less than five times of the distance from focal depth to the epicentre of an earthquake, while Riley wave velocity was utilized to calculate distances more than given amount. In a research study, O'Rourke et al. studied horizontal apparent speed for body waves. They developed an analytical method to assess the shear wave angle of incident. So, apparent speed for shear waves is calculated as

$$
\text { Cs - apparent }=\frac{\mathrm{cs}}{\sin \theta},
$$

where $\theta$ is the incident angle of the shear wave to the horizontal and Cs is the velocity of shear waves in surface soil. Phase velocity of the wave is the same apparent velocity. Unlike body waves, phase velocity depends upon frequency. With regard to the Riley wave, there is relation among wave length $(\lambda)$, frequency, and phase velocity. Figure 13-15 illustrate a scheme of Riley wave propagation with an apparent velocity.

Wave propagation has been found to put strain on the ground. Measuring strain of ground is done by studying simple transitional movement of a wave having fixed shape. It was assumed that velocity and movement of two points throughout a propagation path simply differ in a time lag in which, in turn, it is a function of the distance between two points and the seismic wave velocity. In the same token, maximum tensile or compressive strain of the earth $(g \epsilon)$ in the direction of wave propagation is measured as

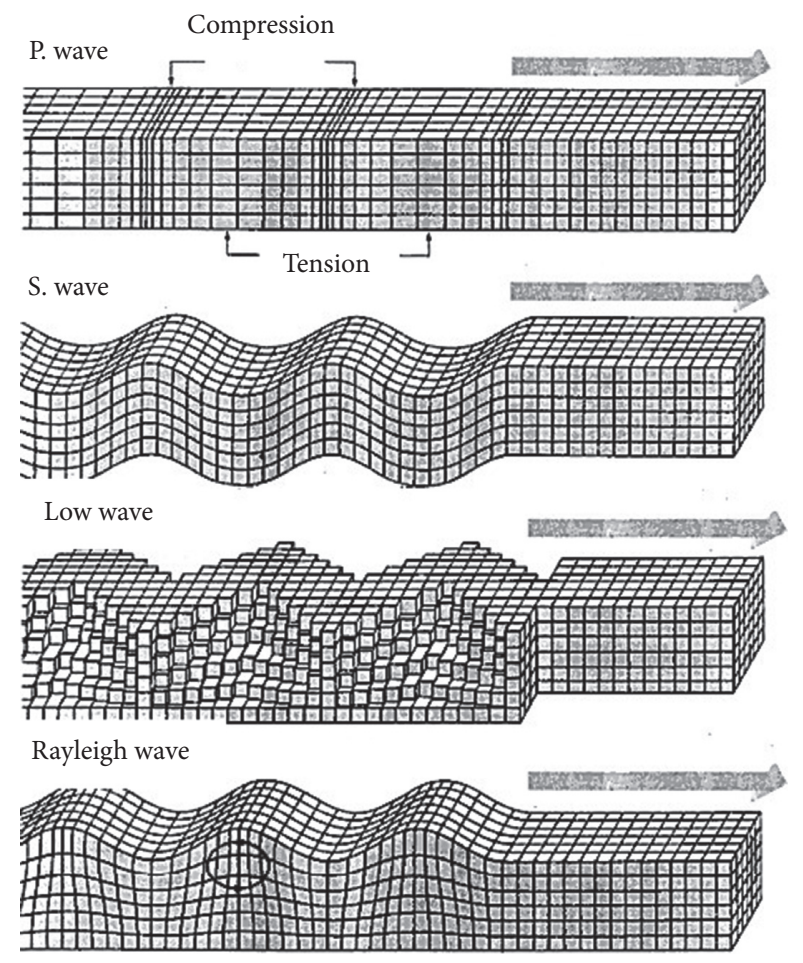

FIgURE 13: Comparing $\mathrm{R}$ and $\mathrm{S}$ waves in designing pipes.

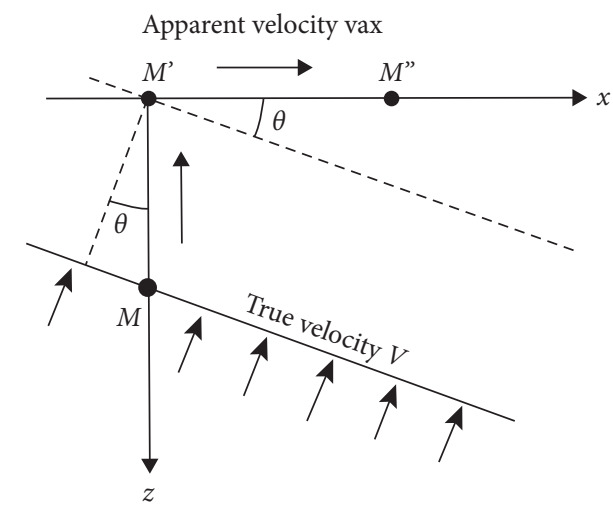

FIGURE 14: Apparent propagation of a shear wave.

$$
\varepsilon g=\frac{\mathrm{Vm}}{C}
$$

where $\mathrm{Vm}$ is the maximum horizontal velocity of the earth in the direction of wave propagation and $\mathrm{C}$ is the apparent propagation velocity of the seismic wave. To propagate a Riley wave, strain parallel with the ground could be measured using the equation above, where $C$ is replaced by the value of phase velocity according to the wave length equivalent to four times of the separation distance (the length of the pipe located between two bridles which is about to analyse). The equation needs to be changed when the given direction is parallel to the line of wave propagation. Generally, as can be seen from the figure below, the wave has angle in both vertical and horizontal plates. So, the equation 


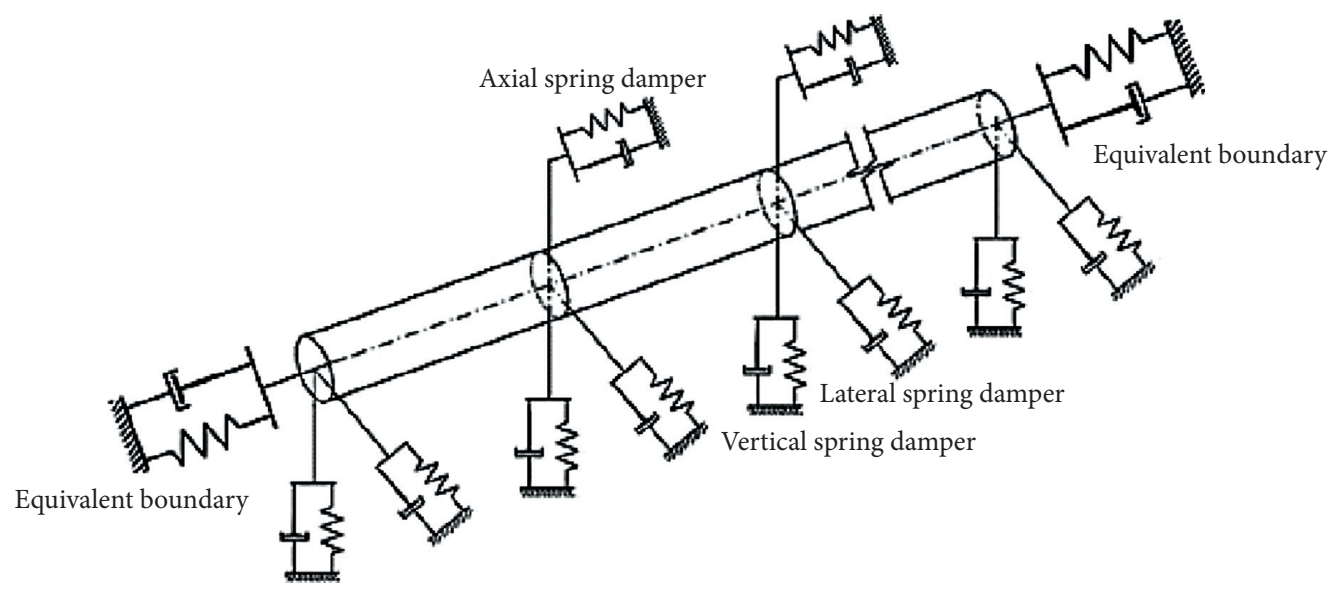

FIgURE 15: Apparent propagation of an $\mathrm{R}$ wave, strain of the ground, and curvature results.

below is used to measure apparent wave velocity in the direction of pipe's axis:

$$
\text { Cs - apparent }=\frac{\mathrm{cs}}{\sin \theta \cdot \cos \gamma} \text {. }
$$

Yeh [17] illustrated that maximum strain of the earth is measured by $45=\theta=\gamma$ in given plates.

3.4. Studying Seismic Behaviour of a Soil-Pipe System concerning Continuous Buried Pipelines. A structure bears bending or axial transformations after an earthquake. Providing satisfying plasticity in order to absorb transformations due to earthquake without decrease in static loading capacity acts as an important design criterion. Generally, developed axial strain throughout a continuous direct pipe depends upon such factors as shape of the earth, transmittal wave length, and soil-pipe interaction forces. Although strain of pipe and soil are assumed equal for small- to medium-sized movements, the same is not true for great strains because of existent slipping between soil and pipe. It has been found to decrease pipe strain compared to that of soil. Newmark [16] put forward a simple method to determine how the pipeline acts when earthquake waves are propagated. Then, other researchers, such as Yeh, revised it.

Seismic movement of the earth, which is defined as the history of velocity-time and velocity-displacement, functions as a transmittal wave with fixed shape. It suggests that two points along the propagation path simply shake by a time lag. Inertia involved in small movement equations is too small to be measured. Later, the assumption was studied by many researchers and their works showed that it acts as a reasonable engineering approximation. It is assumed that no relative movement happens in the soil-pipe interaction, and pipe's strain equals to that of soil. In addition, O'Rourke and El Hamadi developed an analytical method to estimate maximum pipe strain.

The method assumes that first, axial strain in soil equals pipe strain arising from length friction between soil and pipe and second, waves are propagated parallel to the axis of pipe. In a research study, O'Rourke and Jeon [1] compared data collected from three mentioned analytical methods when it came to the continuous pipeline under the Riley wave's propagation. Besides, the model put forward by Takada [18] suggested that pipe is modelled in the form of a shell having a length of $60 \mathrm{D}$ adjacent to the fault, but it could be in the form of an beam element where the distance from the pipe to the fault is almost 300 meters and the extent of soil and pipe slipping and strains are insignificant (Figure 16). All things being equal, soil surrounded the pipe is modelled using soil springs according to the seismic designing regulation of buried oil and gas pipes [19].

In 2004, Takada et al. reported on a new model according to changes in boundary conditions. They suggest that the pipe should be modelled in the junction with the fault in the form of a shell element due to local strain and big transformations just the same as before. Moreover, each point of the shell element is connected to three soil springs in axial, lateral, and vertical directions. Finally, the relation between the axial force $(f)$ and increased length $\Delta L$, which is regarded to boundary conditions for nonelastic springs, is measured as

$$
\begin{gathered}
F(\Delta L)=\sqrt{\frac{3 \mathrm{EAfs}}{2}} \frac{U 01}{6} \Delta L \frac{2}{3}, \quad 0<\Delta L<U 0, \\
\sqrt{3 \mathrm{EAfs}\left(\frac{\Delta L-1}{4 U 0}\right)} \frac{\sigma \mathrm{y} 2 \mathrm{~A}}{2 \mathrm{Efs}}+\frac{U 0}{4},
\end{gathered}
$$

where $Y \sigma$ acts as pipe's yield stress and elasticity modulus. It has been suggested that tensile rupture, local buckling, and thimble buckling are among the most significant damage to continuous pipes while tensile and compression ruptures of pipe joints as well as local bending were the most common damage observed in apart pipeline [20]. Concerning modelling of continuous pipes, Halabian and Hokmabadi [21] stimulated faulting and wave propagation in the laboratory of Isfahan Technological University, Iran, and adopted equivalent boundary conditions put forward by Takada when it came to boundary conditions related to the end of the pipe, so they conducted a parametric study on the behaviour of buried pipelines. 


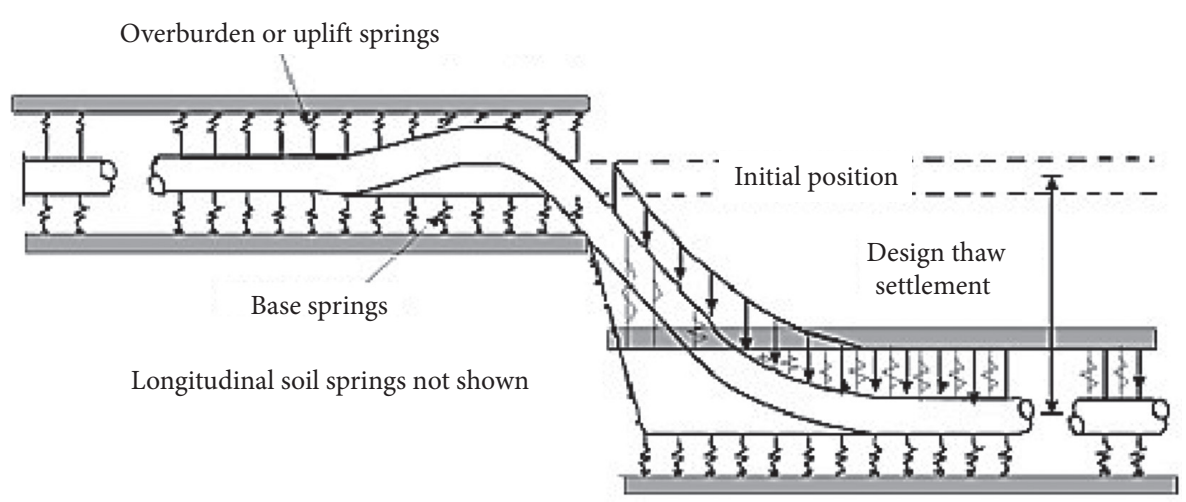

FIGURE 16: Finite-element model of a shell element in collision with the fault.

Rofooei and Qorbani [19] assumed a vertical wave propagation in order to conduct a parametric study on continuous pipes under earthquake loading. They stimulated the pipe and surrounding soil through springs according to the ALA regulation using ANSIS software. Considering data collected from effects of pipe and soil geometric changes on their relative displacement, they observed increase in relocation in the soil-pipe boundary due to decrease in soil aggregation.

\subsection{The Seismic Susceptibility Model concerning Buried} Pipelines. Hazus.sr2i is a guideline on estimating damage to structures due to the earthquake which was developed by FEMA and the national institute of the US Architecture. It is comprised of ways to estimate the extent of earthquake damage to various structures, including lifelines. Accordingly, the guideline suggests that leakage tends to happen because of earthquake waves in which $80 \%$ depends upon maximum earth velocity and $20 \%$ is a function of earth's permanent transformations, while it has been found that pipe breakage proves to be due to earth's big transformations in which $20 \%$ and $80 \%$ depend upon PGA and PGD, respectively.

Furthermore, the method divides pipes into two groups, including frangible and flexible. As a result, susceptibility of flexible pipes decreases by $70 \%$. The likelihood of soil liquefaction has been directly entered to the Hazus model which is assumed as the most significant factor on pipe displacement. The algorithm concerning susceptibility of buried pipes under earthquake waves was found by analysing experimental data collected from four earthquakes in the US and two in Mexico. Then, data were adjusted to the Hazus method.

The guideline divides pipes into small and big groups in order to estimate time required for reconstructing pipelines damaged in earthquakes. Accordingly, the small group includes pipes having a diameter of 20 inch or less while others are put in the big group. The method also estimates days required for reconstruction of the water supply system. The following assumptions suggest how to measure days for repair the pipeline. It takes an equipped four-man team for four and eight hours to repair a leaky and a broken pipe, respectively. It takes an equipped four-man team for six and twelve hours to repair a leaky and a broken pipe, respectively. There is a linear link between repair program and time. As a result, the extent of repairs done on a pipeline which needs $(a)$ days within $(b)$ days with a fixed number of workers is measured $b / a$ (Table 2).

3.6. The Susceptibility Index VI. In this method, the weighted coefficient is assumed as a factor covering pipe diameter $\mathrm{cd}$, conditions of the ground $\mathrm{cg}$, magnitude of the earthquake based on the Mercalli intensity scale ci, pipe passage through the fault $c f$, soil liquefaction $\mathrm{cl}$, and potential land slide occurrence potential. Tables 3-10 give information about weighted coefficients. Susceptibility of each part in the wastewater system is achieved by giving weight to abovementioned factors in different conditions and then multiplying the value by the weighted coefficient of each factor. Considering data from Table 10 and based on values obtained from forgoing equation (6), susceptibility of the wastewater system is divided into three groups, including high, medium, and low. It is worth mentioning that weighted coefficients concerning each factor have been selected based on maximum recorded damage to the buried pipeline in past earthquakes. Table 5 gives information about weighted coefficient regarding conditions of the ground based on different types of soil. In addition, Table 6 illustrates magnitude of an earthquake as well as correspondent improved intensity scale (MMI) in PGA:

$$
\mathrm{VI}=\mathrm{cd} \cdot \mathrm{cp} \cdot \mathrm{cf} \cdot \mathrm{cg} \cdot \mathrm{ci} \cdot \mathrm{cl} \cdot \mathrm{cs} .
$$

\section{Numerical Simulation}

A complete set is comprised of software, hardware, data, models, algorithms, and human resources for collecting, preparing, organizing, storing, updating, processing, and analysing different types of local data. Such a system aims to manage and handle information collected from the reference place in order to make sensible decisions. The data model indicates transformation of the real world, by observing related geometrical relations and descriptive information, to a reasonable and digital one. The model represents all objects in the form of points, lines, or polygon. However, topological data aim to extract relations between phenomena. Existing 
TABle 2: Hazus equations concerning the ratio of damage to a buried pipeline.

\begin{tabular}{lcc}
\hline Type of pipe & The ratio of damage to a PGV pipe per kilometer & The ratio of damage to a PGD pipe per kilometer \\
\hline $\begin{array}{l}\text { Fragile } \\
\text { Flexible }\end{array}$ & $\mathrm{RR}=0.0001^{*}$ PGV2.25 & $\mathrm{RR}=$ prob $^{*}$ PGD0.56 \\
\hline
\end{tabular}

$\mathrm{PR}$ is defined as the extent of damage to the pipe per kilometer

PGV $\left(\mathrm{cm} . \mathrm{s}^{-1}\right)$

PGD (inch)

TABLe 3: Weighted coefficient for diameter of a pipe.

\begin{tabular}{lc}
\hline Coefficient cd & Pipe diameter $(d)$ \\
\hline$D<75 \mathrm{~mm}$ & 1.6 \\
$75 \mathrm{~mm}<d<150 \mathrm{~mm}$ & 1.0 \\
$150 \mathrm{~mm}<d<250 \mathrm{~mm}$ & 0.9 \\
$250 \mathrm{~mm}<d<450 \mathrm{~mm}$ & 0.7 \\
$450 \mathrm{~mm}<d<1000 \mathrm{~mm}$ & 0.5 \\
$d>1000 \mathrm{~mm}$ & 0.4 \\
\hline
\end{tabular}

TABle 4: Weighted coefficient for type of pipe.

\begin{tabular}{lc}
\hline Type of the pipeline & Coefficient $(\mathrm{cp})$ \\
\hline Soft cast iron & 0.3 \\
Cast iron & 1.0 \\
Ceramic & 3 \\
Asbestos & 2.5 \\
Poly ethylene & 0.1 \\
Concrete & 2 \\
\hline
\end{tabular}

TABLE 5: Weighted coefficient for conditions of the ground.

\begin{tabular}{lc}
\hline Type of soil & Coefficient \\
\hline Type I & 0.5 \\
Type II & 1 \\
Type III & 2 \\
Type IV & 2.9
\end{tabular}

TABLE 6: Weighted coefficient for magnitude of the earthquake.

\begin{tabular}{lc}
\hline Magnitude of the earthquake & Coefficient \\
\hline $\mathrm{MMI}<8$ & 1.0 \\
$\mathrm{PGA}<0.25 \mathrm{G}$ & 2.1 \\
\hline $8<\mathrm{MMI}<9$ & \\
$0.25 \mathrm{G}<\mathrm{PGA}<0.45 \mathrm{G}$ & 2.4 \\
\hline $9<\mathrm{MMI}<10$ & 3.0 \\
$0.45 \mathrm{G}<\mathrm{PGA}<0.6 \mathrm{G}$ & \\
\hline $10<\mathrm{MMI}<11$ & 3.5 \\
$0.6 \mathrm{G}<\mathrm{PGA}<0.9 \mathrm{G}$ & \\
\hline $11<\mathrm{MMI}$ &
\end{tabular}

relations between phenomena in local data function as part and particle of some GIS analysing systems. In the raster model, the whole map is divided into a set of small and regular cells called pixel. The raster format is actually composed of an $n * m$ array of pixels.

The geographical information system (GIS) has recently attracted the attention of different engineering fields. The
TABLE 7: Weighted coefficient for passage of the pipeline through the fault.

\begin{tabular}{lc}
\hline Passage of the pipeline through a fault & Coefficient \\
\hline No passage & 1 \\
One passage & 2 \\
Multiple passages & 2.4 \\
\hline
\end{tabular}

TABLE 8: Weighted coefficient for soil liquefaction.

\begin{tabular}{lc}
\hline Liquefaction & Coefficient \\
\hline $0<\mathrm{PL} 1<5$ & 1 \\
$5<\mathrm{PL}<15$ & 2 \\
$\mathrm{PL}>15$ & 2.4 \\
\hline
\end{tabular}

TABLE 9: Weighted coefficient for the land slide potential CS.

\begin{tabular}{lc}
\hline Potential of the land slide & Coefficient \\
\hline No danger & 1 \\
Medium danger & 2 \\
High danger & 2.4 \\
\hline
\end{tabular}

TABLE 10: Classification of the extent of seismic susceptibility of the wastewater system.

\begin{tabular}{lcc}
\hline Color & Susceptibility level & VI index \\
\hline Green & Low & $0<\mathrm{VI}<5$ \\
Orange & Medium & $5<\mathrm{VI}<12$ \\
Red & High & $\mathrm{VI}>12$ \\
\hline
\end{tabular}

ability to interpret and analyse data in such systems and software enables us to review multiple parameters and factors affecting different analyses and achieve reliable results. Research has proved the applicability of GIS to analyse data and extract results in the field of water and wastewater engineering. In the current research, the most well-known software package appertain to geographical information, ArcGIS Desktop 10.1, has been used to analyse data. For the purpose of analysis, first, software's default data and geographical tiers, called GIS READY, were prepared. The process was comprised of improving designing mistakes and then doing a georeferencing operation.

Since most of data were in the form of paper maps, they were first scanned and then by taking the scale of data into account, data were turned into a numerical one. Finally, with regard to available data as well as type of analysis, all data were changed into a roster model based on their effective parameters (Figure 17). 


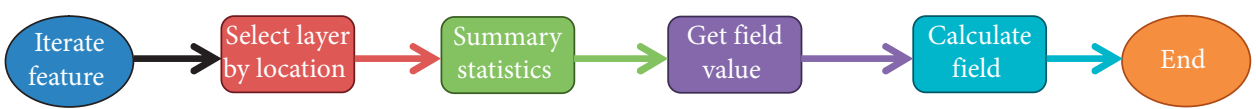

FIGURE 17: The algorithm determining the extent of damage observed under an earthquake wave in GIS.

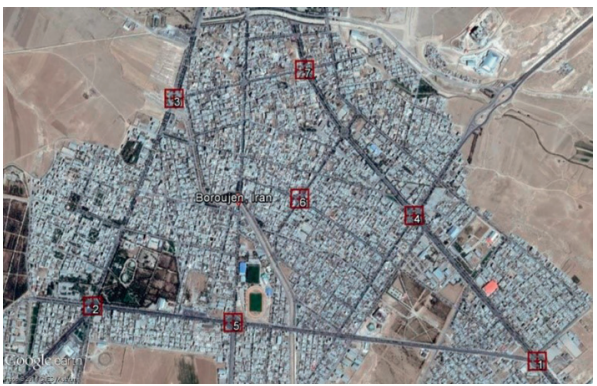

FIGURE 18: Geographical location of Gorgan.

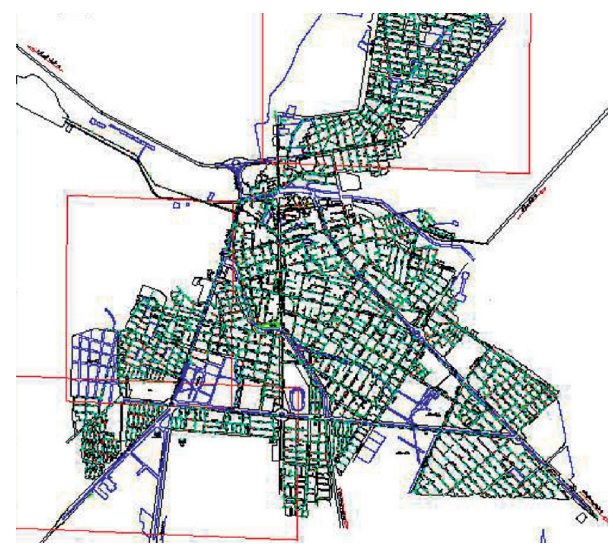

FIGURE 19: The organization map of the urban wastewater system.

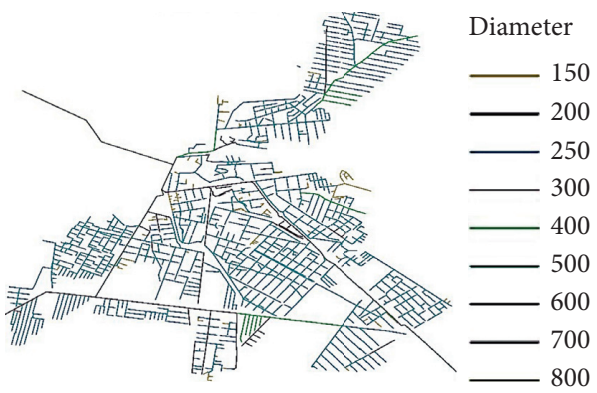

Figure 20: The map of Borujen wastewater system (diameter of pipes).

4.1. Statistical Population. Gorgan, a city in Golestan, Iran, was selected in the current case study research. It has been the first city in the province equipped with the wastewater system. As the city experiences dozens of small earthquakes every day, it is worth studying susceptibility of the wastewater system to earthquake. The wastewater system is 124 meters in length (Figure 18).

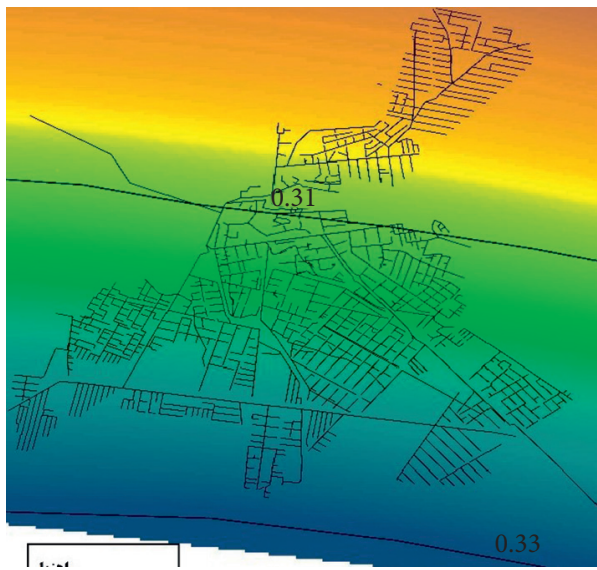

FIgURE 21: The PGA10 map and Borujen's wastewater system.

First, maps developed in AutoCAD software pertinent to the Gorgan wastewater system were collected in order to assess the extent of damage to the system due to earthquakes. Next, maps were turned into GIS data. Both 2 and 10 percent danger analysis maps were adjusted to aerial photos, and then corrected ones were entered into GIS software to measure the seismic susceptibility ratio under maximum land movement.

4.2. Sampling Method and Sample Size. In the current research, two types of data, including maps of seismic analysis and wastewater pipelines' code were used. The former includes curves aligned with velocity of potential approaches of the vertical element which are pertinent to a return period of 75 years for $2 \%$ PGA and a return period of 475 years for $10 \%$ PGA for an estimated 50 year service life.

4.3. The Map of Selected Wastewater System. The Gorgan water and wastewater organization has provided the researcher with given maps as well as a file containing pipelines' codes (Figures 19 and 20). Then, the file entered into the GIS software and improved.

4.4. Data Analysis. Research variables include characteristics of pipes as well as velocity of the earthquake which have been drawn by adjusting rough maps of earthquake velocity and the city's wastewater system (Figures 21 and 22).

\section{Results and Discussion}

Raw data were put into GIS software as input, and two output data were obtained. Figures 23 and 24 illustrate the 


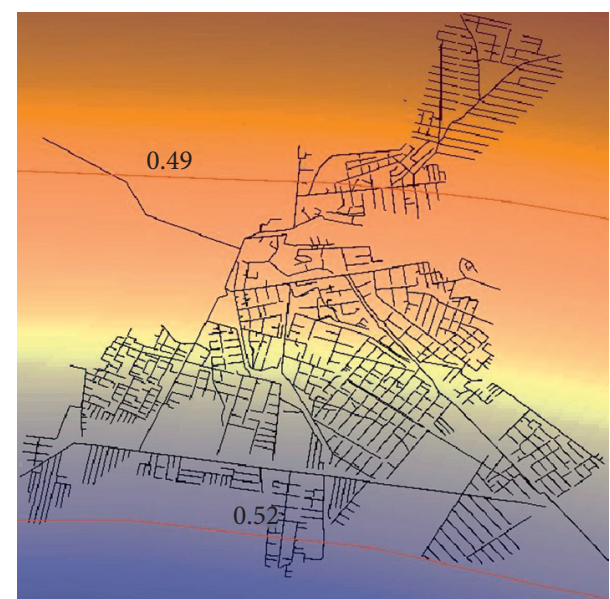

FIgURE 22: The PGA2 map and wastewater system.

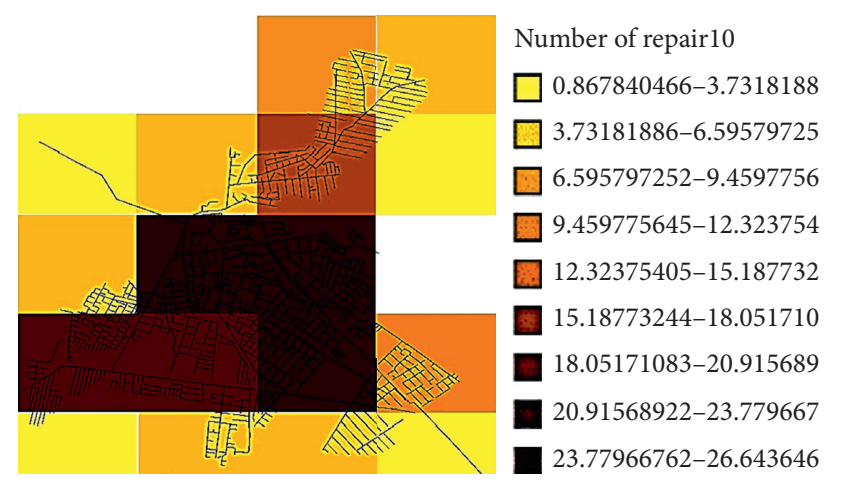

Figure 23: The total number of Hazus SR2 damage under PGA10\%.

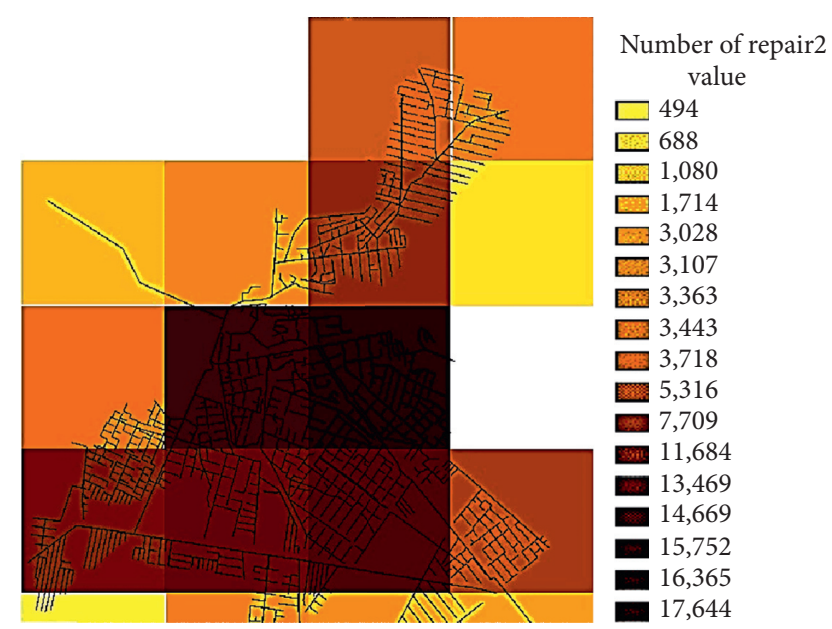

Figure 24: The total number of Hazus SR2 damage under PGA2\%.

extent of damage to pipes using Hazus based on two different earthquake velocities, namely, PGA $2 \%$ and PGA $10 \%$.

Figures 25 and 26 give information about the extent of damage under two different earthquakes according to the VI method.

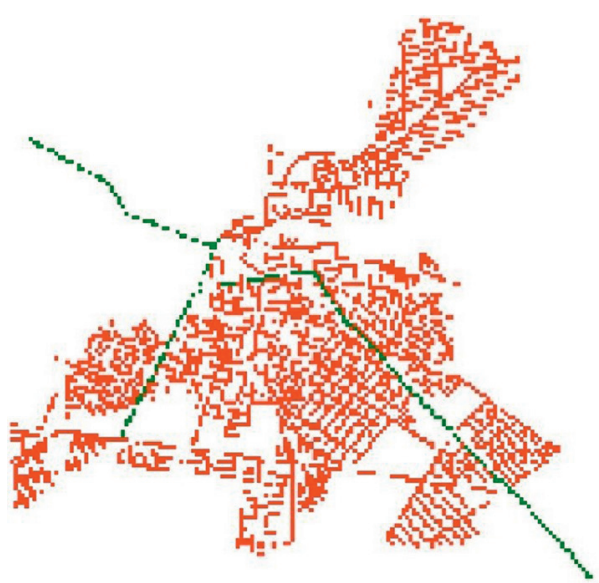

FIgURe 25: The total number of damage under PGA2\% according to the VI method.

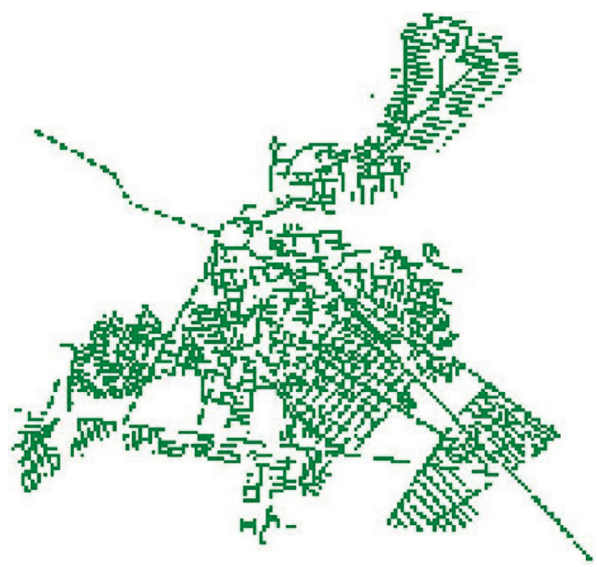

FIgURE 26: The total number of damage under PGA10\% according to the VI method.

\section{Conclusion}

Comparing HAUS and VI methods suggests that the former gives more accurate and detailed data, so it enables authorities to make better decisions for boosting and planning structures and finding their susceptible points. Moreover, as the method helps to find out the extent of damage structures would suffer after occurrence of an earthquake, reconstruction process would be done quickly and precisely.

Considering the point that the region has always been earthquake-prone, reviewing data obtained from maps show a high level of damage. Maps are indicating the first prediction of the current research, that is to say, susceptibility of the wastewater system to occurrence of any earthquake, so it focuses on the necessity for replacing existent pipelines with more resistant ones.

\section{Data Availability}

The data used to support the findings of this study are available from the corresponding author upon request. 


\section{Conflicts of Interest}

The authors declare that there are no conflicts of interest regarding the publication of this paper.

\section{References}

[1] T. D. O'Rourke and S. S. Jeon, "Factors affecting the earthquake damage of water distribution systems, in optimizing post-earthquake lifeline system in optimizing post-life line system reliability," in Proceedings of the Fifth U.S. Conference on Lifeline Earthquake Engineering ASCE, Seattle, WC, USA, 1999.

[2] U. Albayrak, A. Loai, and M. Morshid, "Evaluation of seismic performance of steel lattice transmission towers," Civil Engineering Journal, vol. 6, no. 10, pp. 1-21, 2020.

[3] B. Cai and M. H. Golestan, "Towards bayesian quantification of permeability in micro-scale porous structures," The Database of Micro Networks, vol. 1, no. 4, pp. 1-13, 2020.

[4] H. Shah and S. Chu, "Seismic analysis of underground structural elements," Journal of the Power Division, vol. 100, no. 1, pp. 53-62, 1974.

[5] E. C. Goodling, "Buried piping-an analysis procedure update," in Proceedings of the International Symposium on Lifeline Earthquake Engineering, vol. 77, pp. 225-237, ASME, Portland, Oregon, May 1983.

[6] M. Shinozuka and T. Koike, "Estimation of structural strain in underground lifeline pipes," Lifeline Earthquake EngineeringBuried Pipeline, Seismic Risk, and Instrumentation, vol. 34, pp. 31-48, 1979.

[7] S. Takada and K. Tanabe, "Three-dimensional seismic response analysis of buried continuous or jointed pipelines," Journal of Pressure Vessel Technology, vol. 109, no. 1, pp. 80-87, 1987.

[8] S. Takada, A. Carlo, S. Bo, and X. Wuhu, Current State of the Arts on Pipeline Earthquake Engineering in Japan, The Construction Engineering Research Foundation, Pune, Maharashtra, India, vol. 1, 1992.

[9] L. Dai, D. Wang, T. Wang, Q. Feng, and X. Yang, "Analysis and comparison of long-distance pipeline failures," Journal of Petroleum Engineering, vol. 2017, no. 1, 7 pages, Article ID 3174636, 2017.

[10] Y. Yang, S. Yang, Z. Li et al., "Analysis of hazard area of dispersion caused by leakage from underground gas-storage caverns in salt rock," Advances in Civil Engineering, vol. 2020, no. 1, 11 pages.

[11] M. Cubrinovski, Geotechnical Reconnaissance of the 2010 Darfield (New Zealand) Earthquake, University of Canterbury, Christchurch, New Zealand, 2010.

[12] Y. Maruyama and F. Yamazaki, "Construction of fragility curve for water distribution pipes based on damage datasets from recent earthquakes in Japan," in Proceedings of the 9th US National and 10th Canadian Conference on Earthquake Engineering, Toronto, ON, Canada, July 2010.

[13] J. F. Bird and J. J. Bommer, "Earthquake losses due to ground failure," Engineering Geology, vol. 75, no. 2, pp. 147-179, 2004.

[14] M. Zare and S. Wilkinson, "Earthquake damage in wastewater system and post earthquake repair methodslimitation and practce," in Proceedings of the Australian Earthquake Engineering Society Conference Novotel Bavossa Valley Rwsort, Barossa Valley, South Australia, November 2011.

[15] R. T. Eguchi, "Seismic vulnerability models for underground pipes," in Proceedings of the International Symposium on EarthquakeBehavior and Safety of Oil and Gas Storage
Facilities, Buried Pipelines and Equipment, American Society of Mechanical Engineers (ASME), New York, NY, USA, January 1983.

[16] N. M. Newmark, "Seismic design criteria for structures and facilities, Trans-Alaska pipeline system," in Proceedings of the US National Conference on Earthquake Engineering, Earthquake Engineering Institute, San Francisco, CA, USA, June 1975.

[17] G. Yeh, "Seismic analysis of slender buried beams," The Bulletin of the. Seismological Society of America, vol. 64o, no. 5, pp. 1551-1562, 1974.

[18] S. Takada, N. Hassani, and K. Fukuda, "A new proposal for simplified design of buried steel pipes crossing active faults," Earthquake Engineering \& Structural Dynamics, vol. 30, no. 8, pp. 1243-1257, 2001.

[19] F. R. Rofooei and R. Qorbani, “A parametric study on seismic behavior of continuous buried pipeline due to wave propagation," in Proceedings of the 14th World Conference on Earthquake Engineering, Beijing, China, October 2008.

[20] M. Hosseini and S. Jallili, "Assessment of the nonlineear behavior of connection in water distribution networks for their seimic evaluation," Procedia Engineering, vol. 14, pp. 2878-2883, 2011.

[21] A. M. Halabian and T. Hokmabadi, "A new hybrid model for rigorous analysis of buried pipelines under general faulting accounting for material and geometrical non-linearities with focusing on corrugated HDPE pipelines," Soil Dynamics and Earthquake Engineering, vol. 115, pp. 1-17, 2018. 